\title{
Torakal çıkış sendromu
}

\author{
Thoracic outlet syndrome
}

\author{
S. Aydın Yücetürk
}

Acıbadem Üniversitesi Tıp Fakültesi, Ortopedi ve Travmatoloji Anabilim Dalı, İstanbul

Torakal çıkış sendromu, genellikle boyun, omuz ve kolda ağrı yakınmalarına neden olan ve bu bölgelerin ağrıları ile başvuran hastalarda akla en son gelen bir hastalıktır. Muayenesi zor, tetkik sonuçları genellikle normal olan bu hastalıkta tanı konulduğunda, tedavisi standart değildir. Motor nörolojik kayıp veya akut vasküler nedenlerle başvuran hastalarda ise, tanı konulması son derece kolaydır. Bu derleme yazıda, torasik çıkış sendromu teşhis ve tedavisi ile ilgili genel bilgiler verilirken, özellikle tanıya yönelik algoritma ve kullanılan yöntemlere değinilecektir.

Anahtar sözcükler: torasik outlet sendromu; brakiyal pleksus; sinir kökü kompresyonu, üst ekstremite
Thoracic outlet syndrome generally causes pain in the neck, shoulder and arm; and for the patients seen with these symptoms, generally this syndrome is the last to come in mind. Physical examination is difficult, diagnostic tests are usually normal, and when diagnosed, the treatment is not standard. On the other hand, the diagnosis is quite easy if thoracic outlet syndrome causes motor neurologic deficit or acute vascular problems. This article will present the general information for the diagnosis and treatment of thoracic outlet syndrome, and besides mention the algorithm and methods utilized.

Key words: thoracic outlet syndrome; brachial plexus; nerve root compression, upper extremity

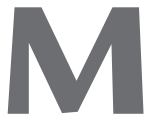

S 150'de, Galen döneminden beri, servikal kot varlığı bilinmektedir. Yaklaşık üç yüz yıl önce semptomlar, 1743'te de Hunald tarafından servikal kostaları tanımlanmış ve 1910'da Murphy, 1. kot rezeksiyonu yapmıştır. ${ }^{[1,2]}$

1927'deki en önemli gelişmelerden birisi, AdsonCoffey'in etiyolojide skalenikus antikus kasını tanımlamasıdır; 1943'te ise Falconer-Weddell, kostoklaviküler basıyı ortaya koymuştur. Günümüzde halen, torasik çıkış (outlet) bölgesi anatomik varyasyonlarının tanımlanması süreci devam etmektedir. Vertebral bölgeden pektoralis majöre kadar olan bölgede, 18 adet kompresyon tanımlanmıştır. Bu, günümüzde en zor tanı konulan hastalıklardan biridir. ${ }^{[1-4]}$

Torasik Çıkış Sendromu (TÇS) üç önemli yapı içerir: 1) subklaviyen arter, 2) subklaviyen ven ve 3 ) brakiyal pleksus. ${ }^{[5]}$ TÇS'ye ve nörovasküler yapılarda basıya neden olan anatomik yapılar olarak; klavikula, 1. kosta ve skalen kaslar, C7-1. kosta arası fibröz bant, klavikula kırıkları, kosta anomalisi (\%10), travma, tümörler, skalen kaslarda fibromusküler bantlar, pleural askı sistemi, klavipektoral bölge, humerus başı ön bölgesi, Langers kası sayılabilir (Şekil 1). ${ }^{[1,3,5,6]}$

Skalen kaslardan olan anterior skalen kas, C3-6 transvers çıkıntılardan başlar ve 1. kostaya, orta skalen kas ise C2-7 transvers çıkıntılardan başlar ve 1. kostaya yapışır. Skalen kas varyasyonları, çok gelişmiş interpedikül kas varlığı, skalen kas keskin kenarı, 1. kaburga üzerinde anormal skalen kas insersiyoları ve yapışma genişliği olup, basıya neden olur. ${ }^{[7]}$ Embriyolojik olarak ise, tek kas olan skalen kas, genelde üç adet olmakla birlikte, sıklıkla dört veya beş adettir. ${ }^{[3]}$ Anterior veya orta skalen kas kenarları, hiperabduksiyon veya omuz düşüklüğünde, nörovasküler yapılarda basıya neden olur. Servikal kostanın olmadığı durumlarda, bu varyasyonlar akla gelmelidir. Proksimalde bası skalen kaslarlara bağlı (interskalen boşluk), distalde basılar ise kostoklaviküler aralık (kostoklaviküler boşluk) ve pektoralis minör kası altında (subpektoral minör boşluk) oluşur. ${ }^{[3]}$

- Illetişim adresi: Dr. S. Aydın Yücetürk, Acıbadem Üniversitesi Tıp Fakültesi, Ortopedi ve Travmatoloji Anabilim Dalı, İstanbul Tel: 0212 - 3064572 e-posta: draydin.yuceturk@gmail.com

- Geliș tarihi: 13 Ekim 2015 Kabul tarihi: 13 Ekim 2015 


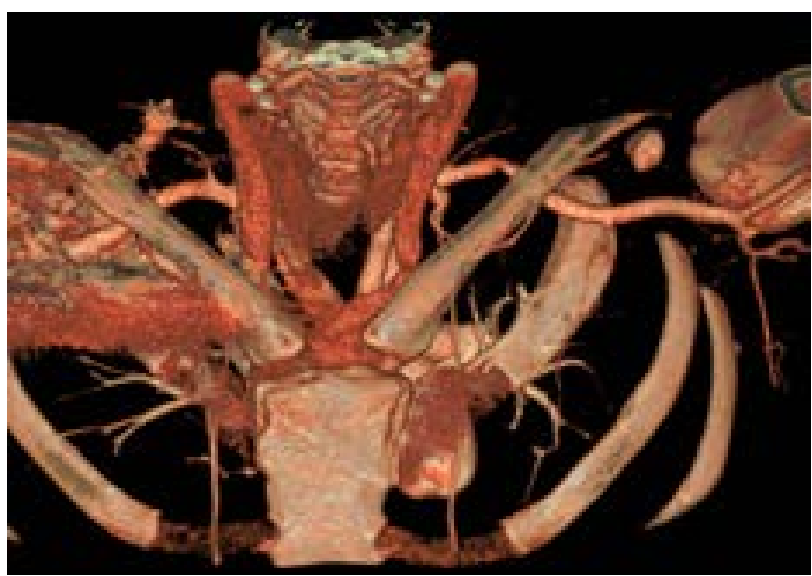

Şekil 1. Skalen kas fibromusküler bant basısına bağlı, solda subklavian arter basısının BT anjiyo görüntüsü.

Torasik çıkış sendromunda (TÇS), basının hangi nörovasküler yapılara olduğu ve basıya neden olan oluşum veya oluşumların hangileri olduğunun ortaya konulması gerekir. Bu oluşumlar, daha önce de değinildiği üzere, fibröz bantlar, kaslar ya da kemik gibi, tanımlanmış anatomik yapılardır. ${ }^{[8]}$

Servikal kosta insidansı \%0,004-1 arası olup, bunların \%90'ı asemptomatiktir; yani, her görülen servikal kosta TÇS tanısı koyduramaz. Kadınlarda servikal kosta, erkeklerden üç kat daha fazla görülür ve $\% 50$ olasılıkla bilateraldir. Eşlik eden kosta anomalileri de sıktır (Şekil 2). ${ }^{[4]}$

TÇS de bası üç çeşittir ve ayrı ayrı ve birlikte görülebilir. Kompresyon (bası) çeşitleri şunlardır: 1) vasküler bası, 2) nörolojik bası ve 3 ) nörovasküler bası. Brakiyal pleksus ve subklaviyen arter, bu dar boşluklardan geçerken, mekanik yaralanmalara maruz kalır. Kas anomalileri ve servikal kot, bu boşlukları daha da daraltır. ${ }^{[1,4]}$

Kişi, tüm hayatı boyunca, ayakta durduğu müddetçe, omuz eklemi ile toraks arasında aşağıya doğru ilerleyici bir düşme meydana gelir; omuz elevatörlerindeki zayıflık ve ağır yük taşıma, bu durumu hızlandırır. Bu ortam, T1'in 1. kaburga çevresinde kıvrılması ve uzamasına neden olur. Ağırlık taşıma, omuz abduksiyonu ve retraksiyonu ile aşırı omuz abduksiyonları, nörovasküler yapılara basıları arttıran hareketlerdir. ${ }^{[4]}$

Hastanın yakınmaları ve bulguları, basıya uğrayan yapıya bağı olarak değişir. Ağrı, yayılım, hipoestezi, parestezi, motor kayıp ve Tinel bulguları, üst ve alt trunkus innervasyon bölgelerine göre olur. ${ }^{[8,9]}$ Üst trunkus basılarında omuz ve dirsek, alt trunkus basılarında ise önkol ve elde bulgular görülür. Semptomatik torasik çıkış sendromu olan hastalarda, boyun ve kol ağrıları, elde parestezi ve bunların, kolun yukarı kalkması, uzanma ve

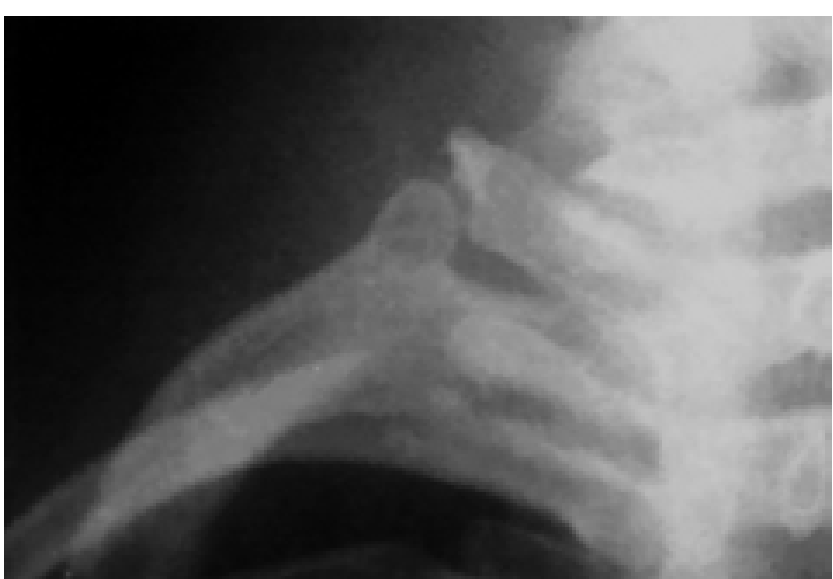

Şekil 2. Kot anomalisi.

ağırlık taşıma ile artması mevcuttur. ${ }^{[4]}$ Ağrı, çoğunlukla ulnar dermatomda hissedilir. ${ }^{[9]}$ Arter basıya uğradığında klaudikasyo-soğukluk, uyuşukluk, yorgunluk; venöz basılarda ise, ağrı, ödem, ağılık ve siyanoz görülür. TÇS semptomları olan hastaların duygusal durumları da iyi değerlendirilmelidir. ${ }^{[5]}$ TÇS, en çok gözden kaçan ve yanIış tanı konulan rahatsızlıklardan biridir. ${ }^{[1,2]}$

\section{Fizik Muayene (Şekil 3)}

\section{Adson Testi}

Derin nefes alınır, boyun ekstansiyona getirilir, ağrılı yöne baş çevrilir, nabız kaybolur. Anterior skalen kas basısını gösterir. Adson testi, \%50 semptomsuz kişide pozitiftir. ${ }^{[4]}$

\section{Kostoklaviküler Manevra}

Omuzlar arkaya ve aşağıya doğru hasta tarafından gerdirilir (sırt çantası taşıma pozisyonunda). Klavikula kosta arası basının belirtisidir.

\section{Hiperabduksiyon Manevrası (Wright 1945)}

Derin nefes alınır, baş ters yöne çevrilir, kola abduksiyon ve eksternal rotasyon yaptırilır. Subkorakoid bası, aksiller arter basısını gösterir. Pleksus üzerinde Tinel belirtisine bakılabilir.

\section{Morley Işareti}

Baş ters tarafa çevrilir, çene yukarıya kaldırılır, derin soluk alınır, omuz posteriora yönlendirilir, eller uyluk üzerinde durur. C7 transvers çıkıntı basısını gösterir ve modifiye Adson testidir.

\section{Allen Belirtisi}

Kol $90^{\circ}$ abduksiyonda, dirsek bükük, kol dış rotasyonda, baş ters tarafa dönük, nabız kontrolü yapılır. 

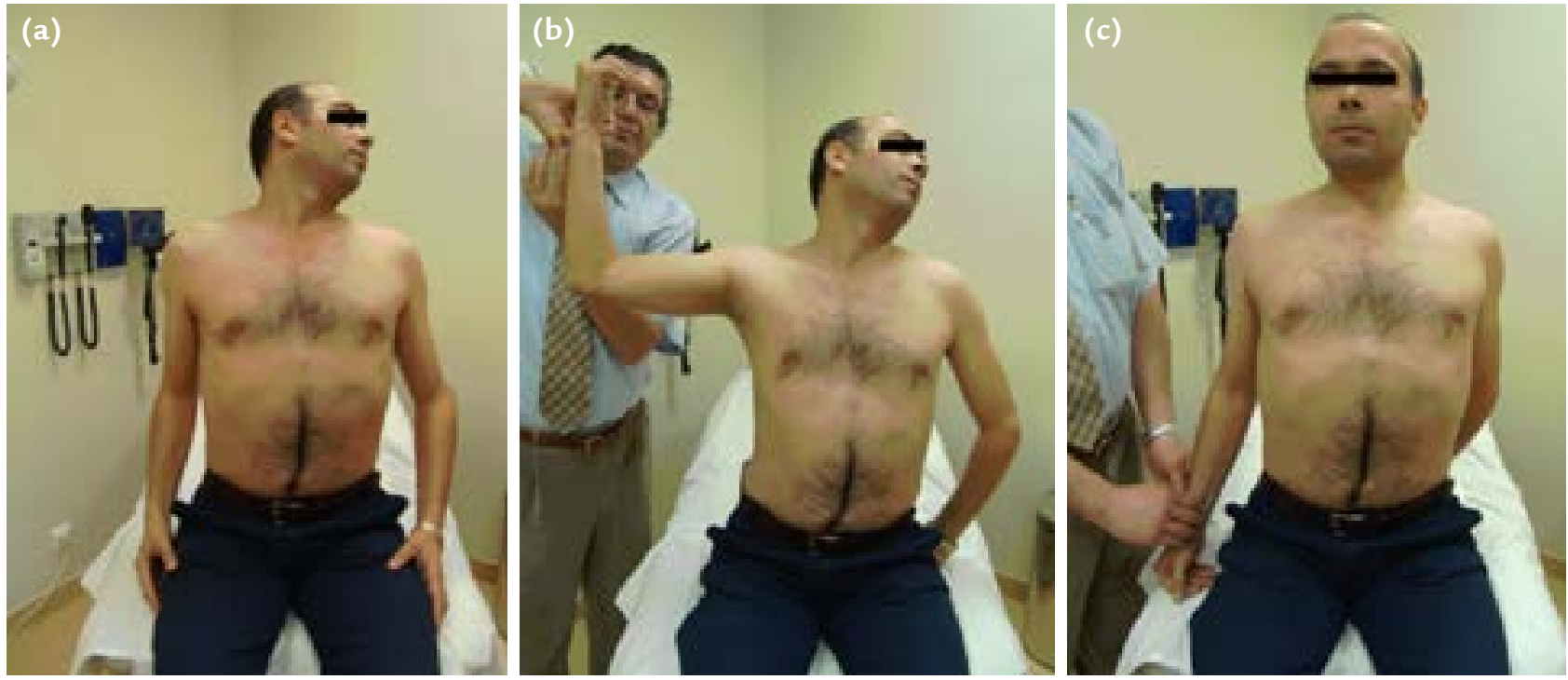

Şekil 3. a-c. Morley testi (modifiye Adson testi) (a), Allen testi (b) ve Kostoklaviküler manevra (c).
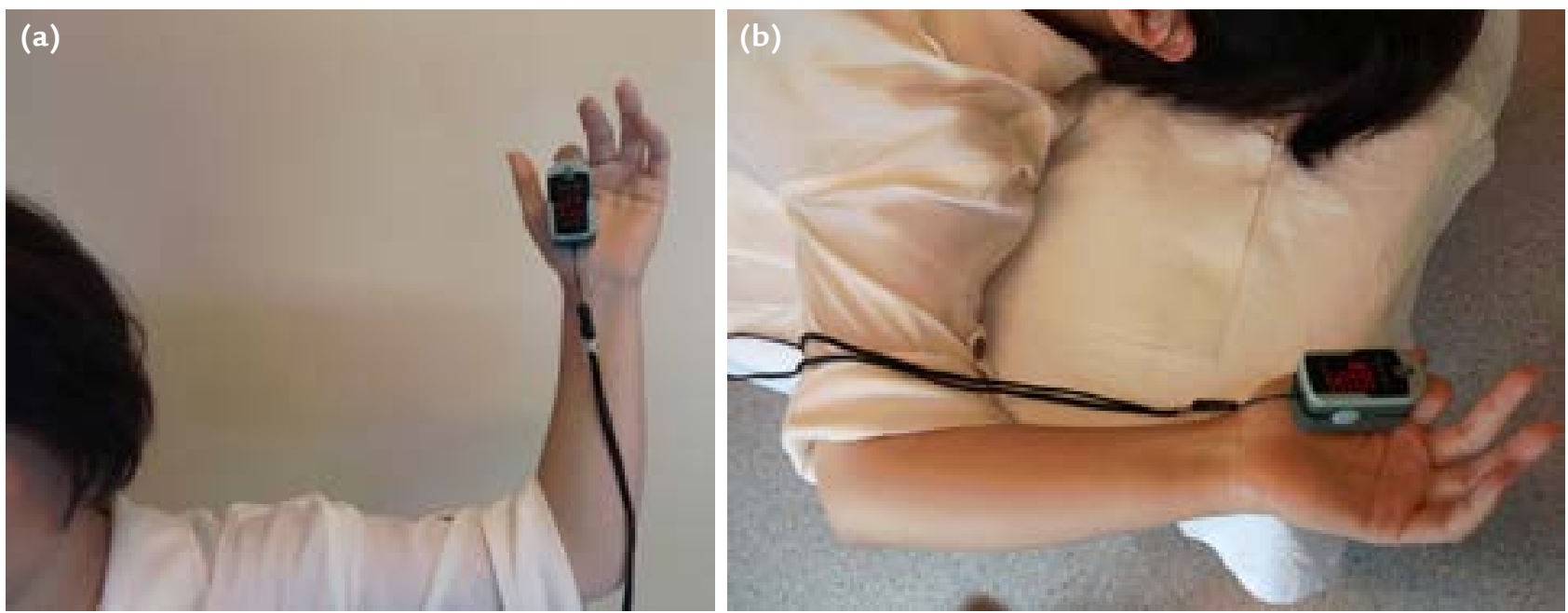

Şekil 4. a, b. Oturarak yapılan muayenede nabız kaybolurken, puls oksimetre ile Allen testi muayenesi (a). Yatarak yapılan muayenede (b), puls oksimetrede nabız kaybolmamaktadır; dolayısıyla, yapılan BT-anjiyografi normal çıkacaktır.

\section{Roos Belirtisi}

Parmakları 20-40 kez açıp kapama sonrası parestezi başlamasıdır.

\section{Chandelier Testi}

Bu, 1-3 dakika hiperabduksiyon testi olup, nabız bozulur. Asemptomatiklerde $\% 50$ pozitifdir.

\section{Falconer ve Weddel Testi}

Omuzlar düşürülür, çene yukarıya kaldırılır, kostoklaviküler bası oluşur. Artere bası yapar ve parestezi oluşur. ${ }^{[4]}$

Ben hastalarımın muayenelerinde nabız kontrolünü parmak pulseoksimetre cihazı ile yapmaktayım.
Cihazda nabzın kaybolması ve satürasyon ölçülememesinin, TÇS muayene bulgusunu daha net ortaya koyduğu düşüncesindeyim.

Kişisel tecrübeme göre, bu muayeneler yatar pozisyonda da tekrar edilmelidir. Bunun nedeni, sonuçta BT-anjiyografi gerekli olacaksa, bu tetkikin ancak yatarak yapılabilecek olmasındandır. Yatarken elde edilen pozitiflik Doppler ultrasonografi (US) ile teyit edildiğinde, bilgisayarlı tomografi(BT)-anjiyografi ile lezyonu yakalama şansı çok artar. Oturarak veya ayakta pozitif bulgu edilen hastada, bu şekilde Doppler US mümkün olmaktadır ama BT-anjiyografide sonuç alma şansı çok düşüktür (Şekil 4). 
Elektromiyografi (EMG) ve radyolojik görüntülemedeki ilerlemelere rağmen, halen en iyi tanı yönteminin fizik muayene olduğu görüşü hakimdir. Bence en iyi tanı yöntemi, fizik muayene ve bulguların tanısal testlerle desteklenmiş olmasıdır.

\section{Tanısal Testler}

X-ray (anomaliler, kırıklar, artritler, akciğer grafisi), Doppler US, dijital subtraksiyon anjiyografi, manyetik rezonans(MR)-anjiyografi, MR görüntüleme (servikal, brakiyal pleksus), venografi, BT-anjiyografidir. ${ }^{[1]}$

Elektrodiyagnostik testler distal ve servikal lezyonların ayırımında yardımcı olup, EMG pozitif hastalarda cerrahi tedavi sonuçları, EMG negatiflere göre her zaman daha iyidir. Ancak TÇS'de, demineralizasyon ve nöral doku ölümü olmaksızın tekrarlayan nöral inflamasyon sonucu ağrı ortaya çıkar ve bu nedenle, EMG normal olup fibrozis kısıtlı olduğunda, görüntüleme yöntemleri de yetersiz kalmaktadı. ${ }^{[9]}$

\section{Destek Tanısal Tetkikler}

\section{Radyolojik Değerlendirme}

Servikal iki yönlü X-ray (C7 görülebilmeli) ile servikal kot, 1. kot anomalisi, klavikula malunion tespiti.

\section{$B T$}

Kemik anomalileri ve tümörle sınırlıdır. Direkt radyolojide bulgu saptanmayan hastalarda, BT ile TÇS tanısı koymak genellikle zordur. Bazen, direkt radyolojide tespit edilemeyen kemik anomalilerinin tespitinde yardımcı olabilir. ${ }^{[10]}$

\section{BT-Anjiyografi}

Klinik olarak pozitif altı hastanın beşi, abduksiyonda yapılan BT-anjiyografide pozitif bulunmuştur. ${ }^{[11]}$

Kişisel tercihim, ideal olan, Doppler US yardımlı BTanjiyografidir. Hastanın TÇS muayenesinde elde edilen pozitif test bulgusu, aynı pozisyonda Doppler US ile teyit edilmeli ve Doppler US de pozitif ise, aynı pozisyonda BT-anjiyografi yapılmalıdır; aksi takdirde, normal test sonuçları ile karşılaşılma olasılığı yüksektir.

\section{$M R$}

Brakiyal pleksus, kas ve fibröz bantları gösterdiği için, en umut verici tetkiklerden birisidir. Pleksusun anomal seyri ve damar birlikteliği ile ilgili görüntü verir. İleride, görüntü kalitesindeki değişimlerle daha yardımcı olacaktır. Dymarkowski ve arkadaşları, üç boyutlu MR görüntülerinin, vasküler bası olan hastalarda tanıya yardımcı olduğunu bildirmişlerdir. ${ }^{[12]}$ Taktografi uygulamaları ise, halen TÇS tanısında sıklıkla uygulanan bir yöntem değildir.

\section{Arteriyel ve Venöz Doppler US}

Vasküler anomaliler, komplikasyonlar, stenoz, poststenotik anevrizma ve parsiyel trombozları gösterir. TÇS'de şu anda en sık kullanılan yöntem olmakla birlikte, bu sendroma ait tanısal manevralar dikkate alınmadan yapıldığında fazla değeri yoktur ve birçok yalancı normal sonuçla karşılaşılmaktadır.

\section{Anjiyografi}

Doppler US tanısı pozitif vasküler lezyonlarda ve kemik anomalilerinde yardımcıdır. Günümüzde, invaziv olmayan yöntemler daha uygundur.

\section{Venografi}

Yüzeyel venlerde dolgunluk, siyanoz ve ödemde yapılmalıdır. Kolda ağırlık hissi, kramp ve parestezi bulguları vardır. Paget-Schroetter sendromu adı verilir. Akut ven trombozlarında Doppler US ile birlikte önemlidir ve yine akut olgularda tromboz tedavisi de bu yöntemle mümkündür (Şekil 5). ${ }^{[1,4]}$

\section{EMG ve Sinir Iletim Çalışmaları}

Dinamik brakiyal pleksus basılarında yardımcı değildir ama 10 günden uzun süredir var olan statik basılarda, tanıda çok yararlıdır. TÇS düşünülen hastalarda rutin yapılmasında yarar vardır. EMG, distal ve servikal sinir lezyonlarının ayırımında yardımcıdır. EMG pozitif hastalarda cerrahi sonuçlar, negatif hastalara göre her zaman daha iyidir. ${ }^{[1,4]}$

\section{Ayırıcı Tanı}

Ayırıcı tanıda, ekstremite ağrısı, servikal disk, servikal omurga veya medulla spinalis sorunları; örneğin, siringomiyeli, supraklaviküler alan sorunları; örneğin, tümör ve tümör metastazları, aksilla ve omuz problemleri, akciğer ve kalp hastalıkları dikkate alınmalıdır.

C5-6 kök irritasyonu (disk, kırık sekeli, spondilozis, tümör), rotator manşet lezyonları, supraskapular tuzak nöropati, algodistrofiler, üst ekstremite diğer tuzak nöropatileri, amiyotrofik lateral skleroz, multipl skleroz, siringomiyeli, skleroderma, von Recklinghausen hastalığı, ayırıcı tanıda akla getirilmelidir. ${ }^{[4,6,13]}$

\section{TÇS'ye Eşlik Eden Tuzak Nöropatiler}

Karpal tünel sendromu \%19-31, radyal tünel sendromu \%2-15, kübital tünel sendromu \%7-9'dur. Bu durumlarda, EMG cerrahi planlamaya yardımcı olur.

\section{Tanı Algoritması}

Hastanın ayrıntılı fizik muayenesi (puls oksimetre ile) sonrası servikal iki, gerekirse dört yönlü X-ray, 


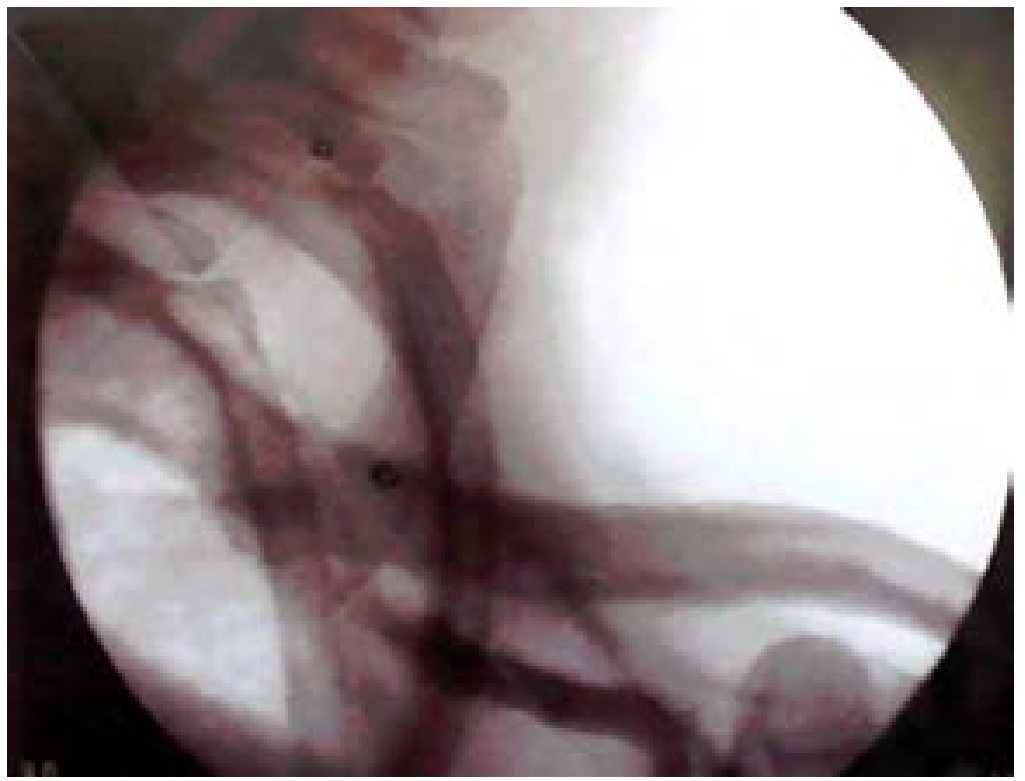

Şekil 5. Paget-Schroetter sendromu; subklaviyen ven trombozunda venografi görüntüsü.

EMG ve üst ekstremite TÇS Doppler US tetkikleri istenir. Doppler US pozitif ise, Doppler US destekli BTanjiyografi yapılır.

Illk sonuçlar sonrası gerekirse boyun MR ve brakiyal pleksus MR de tetkik olarak istenebilir.

Burada EMG, sadece sinirlere yönelik bir tetkik olup, tanıya genellikle vasküler yapılara yönelik yöntemlerle ulaşılmaya çalışıımaktadır. Vasküler yapıya bası görüntülenebilirse, sinir yapılara da bası olduğu düşünülür.

Kişisel tecrübem, görüntüleme tetkikleri TÇS muayene bulguları çerçevesinde yapılmaz ise ve tetkiki yapan kişi, pozitif manevrayı uygulamadan, tetkikte sadece abduksiyon yaptırırsa, büyük olasılıkla yalancı normal sonuç ortaya çıkacaktır. Bu durumda, TÇS'nin tanısında ekip çalışması gerekliliği ortaya çıkmaktadır. Bir diğer önemli konu ise, muayenenin otururken veya ayakta yapılmasının yeterli olmadığı, aynı testlerin yatarken de yapılmasının gerekli olduğudur.

\section{TEDAVi}

Non-steroid anti-inflamatuvar (NSAi) ilaçlar, aktivite kısıtlanması, lokal enjeksiyonlar, fizik tedavidir. (postür düzeltme, omuz güçlendirme, trapez, periskapular adaleler, yüzükoyun yatma). NSAi ilaçlar genelde etkisizdir. ${ }^{[10]}$ Tanısı konmuş hastalarda fizik tedavi ve rehabilitasyon (FTR) ağrıyı arttırabilir; bu durumda tedavi sonlandırılmalıdır. FTR sonrası semptomların \%10-20 hastada arttığı bildirilmiştir. ${ }^{[4]}$

\section{Cerrahi Tedavi}

\section{Cerrahi Girişimler}

Aksiller girişim (kot eksizyonu), servikal girişim (kot, bağ, kas basısı varlığında), aksiller + servikal girişim, supra-infraklaviküler girişimdir; ayrıca, transtorasik girişim, posterior girişim, transklaviküler yaklaşım tanımlanmıştır. ${ }^{[4]}$ Uygulanan yöntemler ise; skalenotomi, skalenektomi, fibrotik bant eksizyonu, klavilektomi, pektoralis minör gevşetme, servikal kot rezeksiyonu, korakoklaviküler bağ eksizyonudur. Amaç, nörovasküler yapılara olan basıyı ortadan kaldırmaktır (Şekil 6).

\section{Komplikasyonlar}

Cerrahi sonrası; uzun torasik sinir felci, şilotoraks, pleksus kesilmesi veya yaralanması, pnömotoraks, yetersiz 1. kot eksizyonu, kostokalviküler sendrom gelişmesi, subklaviyen arter yaralanması, frenik sinir felci, T1 kök avulsiyonu, kozalji sendromu, interkostobrakiyal sinir tam veya kısmi felci, hammock sendromu, yetersiz gevşetme, skar dokusuna bağlı kronik nörit, hematom gibi çok sayıda komplikasyon görülebilir. ${ }^{[1,4]}$ Aksiller yaklaşım sonrası revizyon ameliyatı gerekliliği, Narakas grubunda \%30 oranında saptanmıştır. [4] Kübital tünel sendromunun 8-12 ay sonra görülme oranı sıktır. ${ }^{[1,4]}$

TÇS'ye bağlı yakınması olup da muayene ve EMG sonrası karpal tünel ya da kübital tünel tanısı ile cerrahi uygulanan hasta sayısı, \%30 gibi yüksek bir orandadır. ${ }^{[4]}$ 

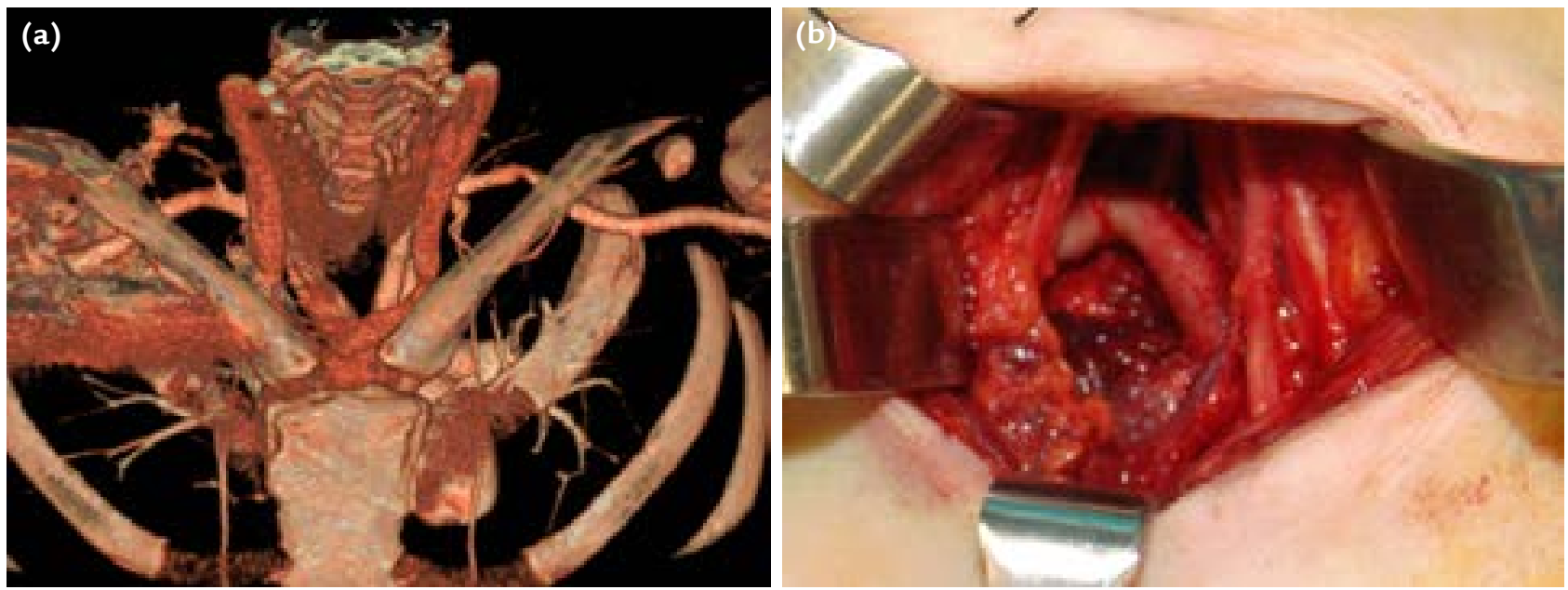

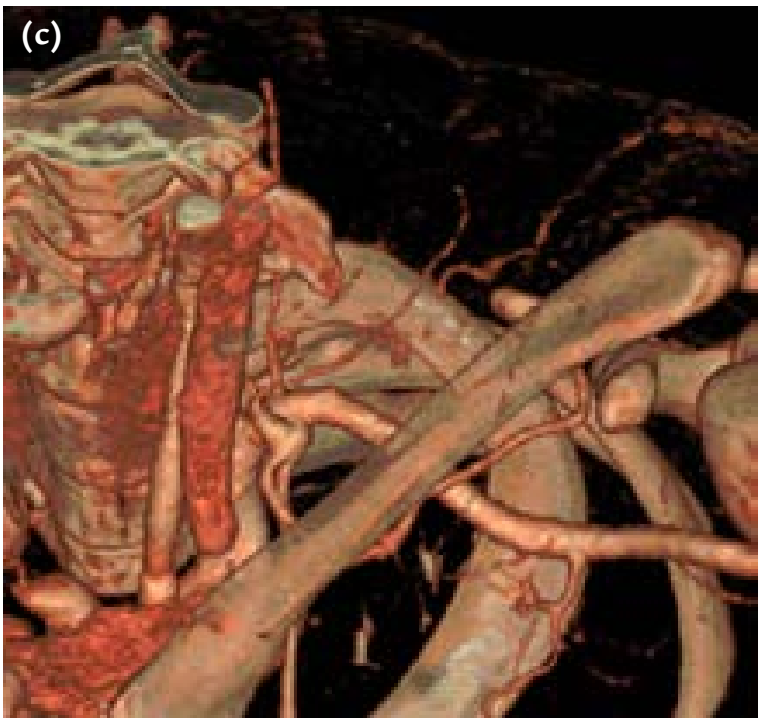

ABD'de, damar cerrahları arasında en fazla malpraktis sorunu, TÇS'ye bağlı cerrahi sonrası görülmektedir. ${ }^{[4]}$

\section{SONUÇ}

TÇS'de tanı zordur, anatomik bilgi gerekir, yardımcı tetkikler sınırlıdır. Ayırıcı tanı mutlaka yapılmalıdır. Cerrahisi zordur ve tecrübe gerektirir. Cerrahi müdahale, lezyonun bulunduğu yere göre değişik yaklaşımlar gerektirir. Kot rezeksiyonlarında aksiller, pleksus yaklaşımlarında ise supraskapular yaklaşımlar önerilmekle birlikte, aynı anda her iki yaklaşımın da kullanılması gerekebilir. Tetkik sonuçları pozitif olan ve lezyon yerinin saptandığı hastalarda, cerrahi sonuçlar daha iyidir.

\section{KAYNAKLAR}

1. Yücetürk A. Torasik çıkış sendromuna mikrocerrahi bakış. İçinde: Öğün TC, editör. Ortopedik Mikrocerrahi Özel Sayısı. Türkiye Klinikleri 2009;2(2):109-114.
Şekil 6. a-c. Ameliyat öncesi BT-anjiyografi; sol subklaviyen artere bası (a). Ameliyatta artere bası görüntüsü (b). Ameliyat sonrası BTanjiyografide, artere basının tamamen düzeldiği görülüyor (c).
2. Atasoy E. Thoracic outlet compression syndrome. Orthop Clin North Am 1996;27(2):265-303.

3. Poitevin LA. Thoracic outlet syndrome, scalene complex and interscalene passages. In: Tubiana R, Gilbert A, editors. Tendon, nerve and other disorders, 1st ed. London: Taylor \& Francis; 2005. p.321-32.

4. Merle M, Borrelyl J, Wilson SW. Thoracic outlet syndrome. In: Tubiana R, Gilbert A, editors. Tendon, nerve and other disorders, 1st ed. London: Taylor \& Francis; 2005. p.333-52.

5. Atasoy E. Thoracic outlet syndrome: anatomy. Hand Clin 2004;20(1):7-14

6. Poitevin LA. Anatomical bases for brachial plexus and subclavian artery compression. In: Tubiana R, Gilbert A, editors. Tendon, nerve and other disorders, 1 st ed. London: Taylor \& Francis; 2005. p.313-20.

7. Atasoy E. Combined surgical treatment of thoracic outlet syndrome: transaxillary first rib resection and transcervical scalenectomy. Hand Clin 2004;20(1):71-82.

8. Redenbach DM, Nelems B. A comparative study of structures comprising the thoracic outlet in 250 human cadavers and 72 surgical cases of thoracic outlet syndrome. Eur J Cardiothorac Surg 1998;13(4):353-60.

9. Ellis W. Thoracic outlet syndrome as a disorder of neurogenic Inflammation. Vasc Endovascular Surg 2006;40(3):251-4.

10. Bilbey JH, Müller NL, Connell DG, Luoma AA, Nelems B. Thoracic outlet syndrome: evaluation with $\mathrm{CT}$. Radiology 1989;171(2):381-4.

11. Hasanadka R, Towne JB, Seabrook GR, Brown KR, Lewis $\mathrm{BD}$, Foley WD. Computed tomography angiography to evaluate thoracic outlet neurovascular compression. Vasc Endovascular Surg 2007;41(4):316-21.

12. Dymarkowski S, Bosmans H, Marchal G, Bogaert J. Threedimensional MR angiography in the evaluation of thoracic outlet syndrome. AJR Am J Roentgenol 1999;173(4):1005-8.

13. Toso C, Robert J, Berney T, Pugin F, Spiliopoulos A. Thoracic outlet syndrome: influence of personal history and surgical technique on long-term results. Eur J Cardiothorac Surg 1999;16(1):44-7. 